\title{
Fabrication of a Miniature Multi-Parameter Sensor Chip for Water Quality Assessment
}

\author{
Bo Zhou ${ }^{1,2}$, Chao Bian ${ }^{1, *}$, Jianhua Tong ${ }^{1}$ and Shanhong Xia ${ }^{1}$ \\ 1 State Key Laboratory of Transducer Technology, Institute of Electronics, Chinese Academy of Sciences, \\ Beijing 100190, China; bzhou92@163.com (B.Z.); jhtong@mail.ie.ac.cn (J.T.); shxia@mail.ie.ac.cn (S.X.) \\ 2 School of Electronic, Electrical and Communication Engineering, University of Chinese Academy of \\ Sciences, Beijing 100080, China \\ * Correspondence: cbian@mail.ie.ac.cn; Tel./Fax: +86-10-5888-7187
}

Academic Editor: Vittorio M.N. Passaro

Received: 17 November 2016; Accepted: 9 January 2017; Published: 14 January 2017

\begin{abstract}
Water contamination is a main inducement of human diseases. It is an important step to monitor the water quality in the water distribution system. Due to the features of large size, high cost, and complicated structure of traditional water determination sensors and devices, it is difficult to realize real-time water monitoring on a large scale. In this paper, we present a multi-parameter sensor chip, which is miniature, low-cost, and robust, to detect the $\mathrm{pH}$, conductivity, and temperature of water simultaneously. The sensor chip was fabricated using micro-electro-mechanical system (MEMS) techniques. Iridium oxide film was electrodeposited as the $\mathrm{pH}$-sensing material. The atomic ratio of $\operatorname{Ir}(\mathrm{III})$ to $\operatorname{Ir}(\mathrm{IV})$ is about 1.38 according to the X-ray photoelectron spectroscopy (XPS) analysis. The $\mathrm{pH}$ sensing electrode showed super-Nernstian response $(-67.60 \mathrm{mV} / \mathrm{pH})$ and good linearity $\left(\mathrm{R}^{2}=0.9997\right)$, in the range of $\mathrm{pH} 2.22$ to $\mathrm{pH} 11.81$. $\mathrm{KCl}$-agar and epoxy were used as the electrolyte layer and liquid junction for the solid-state reference electrode, respectively, and its potential stability in deionized water was $56 \mathrm{~h}$. The conductivity cell exhibited a linear determination range from $21.43 \mu \mathrm{S} / \mathrm{cm}$ to $1.99 \mathrm{mS} / \mathrm{cm}$, and the electrode constant was $1.566 \mathrm{~cm}^{-1}$. Sensitivity of the temperature sensor was $5.46 \Omega /{ }^{\circ} \mathrm{C}$. The results indicate that the developed sensor chip has potential application in water quality measurements.
\end{abstract}

Keywords: water quality; MEMS; pH electrode; conductivity cell; iridium oxide; electrodeposition

\section{Introduction}

Protection of human health is one of the goals of social development, in which water plays an extremely important role. However, the development of industry and agriculture has resulted in water contamination as one of the unintended consequences. Due to the continued deterioration of water sources, the number of water-related diseases and deaths is increasing annually [1]. Therefore, it is intensely demanded to construct monitoring and early warning systems for water quality. Water quality can be assessed from various aspects, through measuring many parameters, including $\mathrm{pH}$, oxidation reduction potential (ORP), conductivity, heavy metal, dissolved oxygen (DO), and so on.

It is cost-consuming and complicated to detect various contaminations separately. Hence, some commercial integrated detection systems have become available [2], which mainly rely on the combination of traditional water sensors, such as bulk $\mathrm{pH}$ electrodes and conductivity sensors. Yet, these probes are unsuitable for being deployed on a large scale, because of the relatively high price, complicated structure, and large size. With the progress of microfabrication technologies, some MEMS-based solid sensors for water monitoring have been proposed, such as the Hemin-based DO sensor [3] and carbon nanotube-based free chlorine sensor [4]. Researchers also have paid attention to developing novel integrated sensors that are compact and low-cost for determination of 
multiple parameters simultaneously. For instance, Zhuiykov et al. [5] have reported an integrated multi-sensor based on screen-printed $\mathrm{RuO}_{2}$ thick films to detect the main parameters of water, such as $\mathrm{pH}$, temperature, DO, conductivity, and turbidity. Guijarro et al. [6] have presented a multi-parametric biochip fabricated by MEMS technique, which was capable of simultaneously detecting bioactive pollutants in water. In addition, Wang et al. [7] proposed a microelectrode for simultaneous detection of copper and lead heavy metallic ions.

One goal of this research is to develop a multi-parameter sensor, which has the characteristics of low cost, small size, and convenient operation, for water quality detection. The sensor was expected to be used in a distribution measurement system, where numerous environmental sensors might be emplaced. The proposed sensor in this paper is competent for the detection of $\mathrm{pH}$, conductivity, and temperature in water. The World Health Organization (WHO) recommends that the $\mathrm{pH}$ of drinking water should be maintained in the range of 6.5 to 8.5 [8]. Some problems might happen if $\mathrm{pH}$ value of the drinking water goes outside the specified range, such as leaching, nitrification, or the presence of microorganisms, which may lead to the gastrointestinal irritation or corrosion of metal pipes [9]. On the other hand, conductivity varies with the dissolved inorganic salts, and, thus, serves as an important factor for indicating ionic contaminations [1]. Temperature is also an important parameter to evaluate water quality and, additionally, it is a dependent factor of the $\mathrm{pH}$ value and conductivity. Thus, it is of great significance to develop a miniature and low-cost sensor to measure these three parameters simultaneously.

Traditional glass composite $\mathrm{pH}$ electrodes are not suitable for the application in integrated sensors because of the size limitation and brittleness. In order to overcome these problems, researchers have proposed sophisticated alternative $\mathrm{pH}$ sensors, such as optical fiber $\mathrm{pH}$ sensors [10], ion-selective field-effect transistors [11], solid-state $\mathrm{pH}$ sensors [12], and hydrogel film $\mathrm{pH}$ sensors [13]. There are extensive studies on potentiometric $\mathrm{pH}$ sensors based upon metal oxides, such as $\mathrm{RuO}_{2}$ [14], $\mathrm{Ta}_{2} \mathrm{O}_{5}$ [15], $\mathrm{SnO}_{2}$ [16], $\mathrm{TiO}_{2}$ [12], and $\mathrm{IrO}_{2}$ [17], due to the features of mechanical stability, easy integration, and direct electrical response. Among the abundant metal oxides, iridium oxide $\left(\mathrm{IrO}_{\mathrm{x}}\right)$ is one of the most promising $\mathrm{pH}$-sensing materials, owing to the fast response, chemical stability, and broad $\mathrm{pH}$ sensitive range $[17,18]$.

There are several methods for the preparation of IrOx, including thermal oxidation [19], sputtering [17], sol-gel [20], and electrodeposition [21]. The properties of IrOx may vary with the preparation methods, which affects the performances of IrOx-based $\mathrm{pH}$ sensors. For example, IrOx films prepared by sputtering or thermal oxidation are dense and anhydrous, which have a sensitivity close to $60 \mathrm{mV} / \mathrm{pH}$. Whereas, electrochemical methods generate loose and hydrated films, which show uncertain responses in the range of 60 to $90 \mathrm{mV} / \mathrm{pH}$ [22]. Some merits and demerits of these fabrication methods have been described in [23]. In spite of the unpredictable potential response and variation in stability for electrodeposited iridium oxide films, electrodeposition is still an attractive way to synthesize $\mathrm{IrO}_{x}$ for $\mathrm{pH}$ sensors, since there are no requirements for high-temperature operation, vacuum environment, complicated instruments, and expensive targets.

Although many studies have been done on the mechanism of IrOx electrodeposition, there is no consistent explanation to it. Yamanaka [24] and other researchers [25-27] supposed that IrOx was deposited on the surface of electrode because the carbon-carbon bonds in the oxalate ligand are oxidized to form $\mathrm{CO}_{2}$. However, there are no report directly presenting the decomposition process of mono oxalate complexes. In the Yamanaka solution, Patrick and coworkers [28] found that there were only multinuclear oxyhydroxides and nanoparticles, instead of oxalate complexes, based on which oxalic acid was perceived to merely act as a stabilizing agent. On the other hand, similar IrOx films were prepared using the solutions containing no oxalate ligand [29-31], which implied that the deposition may not involve the oxidation of oxalate complex. Recently, researchers seemingly agree with that water is the actual species undergoing oxidization in the deposition of IrOx. Zhao et al. [31] attributed the deposition to the oxidation of the water near the anode. They suggested that the releasing $\mathrm{H}^{+}$ions lower the local $\mathrm{pH}$, which induces the acid 
condensation of $\mathrm{IrO}_{\mathrm{x}} \cdot \mathrm{nH}_{2} \mathrm{O}$ nanoparticles. This postulation matches that presented in [32], where the authors synthesized the $\mathrm{IrO}_{x}$ nanoparticles from a $\mathrm{K}_{2} \mathrm{IrCl}_{6}$ solution, and found that lower $\mathrm{pH}$ facilitates the condensation of IrOx nanoparticles. In addition, Heather et al. [29] proposed that a loose polymeric network was precipitated at the surface of electrode, as the result from the oxidization of the water coordinated to $\operatorname{Ir}(\mathrm{IV})$.

The reference electrode is an important component in electrochemical measurements. Although some types of standard reference electrodes are efficient, they usually have the features of large size and complicated structure, which limits their applications in integrated sensors [33]. For instance, an $\mathrm{Ag} / \mathrm{AgCl}$ reference electrode is the most practical, but reducing its scale is difficult because of the unavoidable inner liquid electrolyte and glass tubes. To realize integrated sensors, pseudo-reference electrodes were often integrated on chips using modern fabrication technology. However, such reference electrodes have unstable potentials [34]. The miniaturized liquid junction reference electrode has a better performance than pseudo-reference electrodes, but there are still some challenges, such as sealing a small volume of solution [35] and its maintenance [36]. Thus, it is more applicable for miniature sensors to develop solid-state reference electrodes, where the inner electrolyte is solid [33].

Conductivity sensors are classified into two types: contacting and inductive sensors [37]. Contacting sensors may have two, three, or four electrodes. A four-electrode configuration was perceived more accurate, eliminating the errors caused by polarization and double layers, compared to the conductivity sensors which only have two electrodes [38]. On the other hand, different cell geometries were designed to realize accurate detection of conductivities in various applications. Parallel planar electrodes were usually used to construct miniature conductivity cells [39-41], whereas, Heather et al. [42] have introduced a conductivity cell of circular geometry fabricated on the liquid crystal polymer substrate using printed circuit board (PCB)-MEMS technique, a concept that fabricates MEMS through PCB processes. Then the proposed sensor has been successfully employed in coastal salinity measurements [43]. The concentric circular structure defined the directionless profiles, preventing additional calibration. Although the PCB-MEMS technique is cost-efficient and rapid, these two fabrication processes cannot be carried out simultaneously, which might lead to the problems of mass production, and compatibility with the fabrication process of other sensors.

In this paper, we reported the design, fabrication, and experimental results of an integrated sensor. The electrode array, including a four-electrode circular conductivity cell, three-terminal resistive temperature detector (RTD), and substrate electrodes, was fabricated by MEMS techniques. The amorphous hydrous IrOx film was electrodeposited on Pt electrode for $\mathrm{pH}$ sensing. A miniaturized reference electrode was formed as reference for $\mathrm{pH}$ detection. According to the experimental results, the sensing electrodes on the chip exhibited good performances as intended. The cost of each device is low, since it can be produced in batches. Moreover, the sensor was suitable for various applications, such as remote and distributed measurements, because of the features of small size and mechanical robustness.

\section{Experimental}

\subsection{Reagents and Instruments}

Iridium (IV) chloride (99.95\%) was purchased from Alfa Aesar Co. (Haverhill, MA, USA). Hydrogen peroxide (30\%), potassium carbonate, oxalic acid, boric acid, phosphoric acid, sulphuric acid, potassium chloride, sodium chloride, and ferricyanide were purchased from Beijing Chemical Works Co. (Beijing, China). All chemicals were analytical grade and used without further purification. All of the water used in the experiments was deionized $(18 \mathrm{M} \Omega \cdot \mathrm{cm})$ with a Millipore Direct-Q 3 UV (ultraviolet) system (Merck Millipore Co., Billerica, MA, USA). A $\mathrm{KCl}$ saturated Ag/ AgCl reference electrode was used as a reference, and all potentials were referred to this unless there is an explicit description. 
A CHI620e (CH instruments Co., Shanghai, China) electrochemical workstation was used to control the electrochemical experiments. The $\mathrm{pH}$ of solutions was verified with a pHS-3C meter (Shanghai INESA Scientific Instrument Co., Shanghai, China). The surface morphology of the IrOx film was investigated using a field emission scanning electron microscopy (FE-SEM) of Merlin Compact (Zeiss Co., Oberkochen, Germany). The chemical composition of the IrOx film was detected by an imaging X-ray photoelectron spectrometer of Axis Ultra (Kratos Analytical Co., Manchester, United Kingdom). The resistance of the RTD was determined using a digital multimeter Agilent 34410A (Agilent Technologies Co., Santa Clara, CA, USA).

\subsection{Design}

The multi-electrode consisting of a $\mathrm{pH}$ sensing electrode, an $\mathrm{Ag} / \mathrm{AgCl}$-based solid-state reference electrode, a four-terminal conductivity cell, and a three-end RTD was distributed on the silicon chip, as shown in Figure 1a. Sputtered Pt was used as the materials for conductivity and temperature sensing, because of its good electrical conductivity and temperature characteristic. Additionally, $\mathrm{Pt}$ acts as the substrate electrode for $\mathrm{pH}$ sensing. The hydrous $\mathrm{IrOx}$ film was electrodeposited on the Pt surface for $\mathrm{pH}$ sensing. In order to prevent introducing an external macroscopic reference electrode, a solid-state reference electrode was integrated on the chip. $\mathrm{Ag} / \mathrm{AgCl}$ ink was coated on the $\mathrm{Pt}$ electrode. Agar gel containing $\mathrm{KCl}$ was used as the inner electrolyte, replacing the liquid junction. Epoxy adhesive keeps the agar from directly contacting to sample solutions. The conductivity cell was designed to be a four-terminal configuration, so that the effect of double electric layer capacitance can be prevented. In the measurement of conductivity, an alternative exciting signal should be applied to the electrodes, which may cause interference with other components. Thereby, our conductivity sensor has a circular geometry, which keeps the electrical field within the defined region from disturbing the other components. Moreover, the RTD has a three-end structure, eliminating the errors caused by lead impedance.

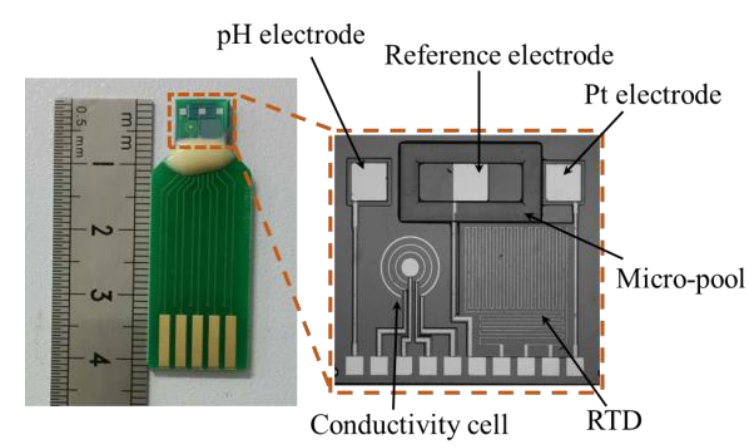

(a)

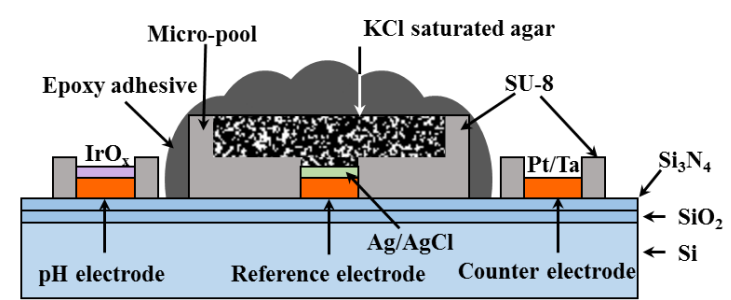

(b)

Figure 1. (a) Photograph of the multi-parameter sensor chip; and (b) a cross-sectional view of the $\mathrm{pH}$ sensor; the third (right) electrode acts as the counter-electrode for the electrodeposition of IrOx.

\subsection{Fabrication of Multi-Parameter Sensor Chip}

Standard MEMS techniques were used to fabricate the sensor chip. At first, a p-type silicon wafer was treated by a thermal wet oxidation process and nitration process of low-pressure chemical vapor deposition (LPCVD). Secondly, the substrate metal layer was deposited on the wafer by a direct current (DC) magnetron sputtering method, and then patterned using standard photolithographic and lift-off techniques. The thickness of Pt and Ta (adherent layer) were $300 \mathrm{~nm}$ and $30 \mathrm{~nm}$, respectively. A layer of SU-8 negative photoresist was used as an insulation layer, which defines the sensing areas of the electrodes and its pads. Meanwhile, a micro-pool surrounding the reference electrode was formed using SU-8. Specifically, the first SU-8 layer was spin-coated on the wafer and explored with ultraviolet (UV) light. Then, a second layer of SU-8 was immediately coated and explored. Next, 
one-step development was carried out to shape the insulation layer, combined with the micro-pool. After that, the wafer was diced into chips with a size of $8 \mathrm{~mm} \times 7 \mathrm{~mm}$. Finally, the individual chips were wire-bonded and encapsulated on PCBs.

\subsection{Fabrication of the Solid State Reference Electrode}

The reference electrode was made in three steps. Firstly, $\mathrm{Ag} / \mathrm{AgCl}$ ink was coated on the $\mathrm{Pt}$ electrode, followed by curing at $90{ }^{\circ} \mathrm{C}$ for $1 \mathrm{~h}$. Then, an appropriate amount of $\mathrm{KCl}$-saturated agar was sealed in the micro-pool with epoxy adhesive. Finally, we removed the potential gas bubbles in a vacuum desiccator, and then left the electrode at room temperature for about $48 \mathrm{~h}$ before coagulation of the epoxy adhesive.

\subsection{Preparation of $\mathrm{pH}$ Sensing Electrode}

The IrOx was electrodeposited with a solution introduced by Yamanaka [24]. Briefly, an amount of $0.075 \mathrm{~g}$ iridium (IV) chloride was dissolved in $50 \mathrm{~mL}$ deionized water with magnetic stirring for $30 \mathrm{~min}$. Then, $0.5 \mathrm{~mL}$ hydrogen peroxide $(30 \%)$ was dripped into the solution with stirring for another $10 \mathrm{~min}$. Subsequently, $0.25 \mathrm{~g} \mathrm{C}_{2} \mathrm{H}_{2} \mathrm{O}_{4} \cdot \mathrm{H}_{2} \mathrm{O}$ was added and the solution was kept stirring for $10 \mathrm{~min}$. As the next step, we adjusted the solution $\mathrm{pH}$ to 10.5 with potassium carbonate. Finally, the solution was left at room temperature for at least two days until a stable state was reached.

A three-electrode system was employed to electrodeposit the $\mathrm{IrOx}$. The fabricated $\mathrm{Pt}$ microelectrode was connected to the electrochemical workstation, acting as working electrode, with an $\mathrm{Ag} / \mathrm{AgCl}$ (sat. $\mathrm{KCl}$ ) as the reference electrode, and the third microelectrode on the chip as the counter electrode. After being electrochemically cleaned in $0.05 \mathrm{M} \mathrm{H}_{2} \mathrm{SO}_{4}$, the electrode was immersed in the electrolyte. Deposition was carried out by cyclic voltammetry. After that, the electrode was rinsed with deionized water and dried with fresh air. A cross-sectional view of the $\mathrm{pH}$ sensor is showed in Figure $1 b$.

\subsection{Measurement Procedure}

The properties of IrOx film were investigated with SEM and XPS. Therefore, information can be collected about the morphology and chemical composition of the film. The $\mathrm{pH}$ sensing electrode was tested by measuring the open-circuit potential (OCP). Sensitivity of the $\mathrm{pH}$ sensing electrode was validated with solutions of different $\mathrm{pH}$ levels. Dynamic properties was investigated by a titration test. The performance of the on-chip solid state reference electrode was investigated by cyclic voltammetry (CV) and potentiometry, with a standard $\mathrm{Ag} / \mathrm{AgCl}$ reference acting as a comparison. The conductivity measurement was conducted with standard buffer solutions of various conductivities. Finally, a water bath experiment was carried out to calibrate the temperature sensor. All of the measurements were performed at room temperature, except for the calibration of the temperature sensor.

\section{Results and Discussion}

\subsection{Electrodeposition of $\operatorname{IrOx}$}

The properties of the IrOx film depend on the composition and morphology of the oxide film, which are mainly dominated by the preparation condition [44]. Thus, potential was investigated as the parameter which could affect the surface morphology of IrOx film, and a SEM was employed to observe morphologies of the films. Different potential ranges $(0-0.6 \mathrm{~V}, 0-0.7 \mathrm{~V}$, and $0-0.75 \mathrm{~V})$ were carried out, while the scan rate $(100 \mathrm{mV} / \mathrm{s})$ and the number of voltammetric cycles (100) were kept constant. The SEM images of prepared films were displayed in Figure 2, which illustrate that IrOx nanoparticles have been deposited on the surface of electrode. By comparing the films obtained with different potential conditions, it could be found that a more positive potential induced a lager particle size, and rougher surface. We suppose that a higher potential promotes the process of nucleation of $\mathrm{IrO}_{\mathrm{x}}$ nanoparticles. Considering the films with rougher surface provide larger number of adsorption 
centres of $\mathrm{pH}$ measurements, a higher anodic potential is desirable. However, if we kept raising the anodic potential limit to $0.75 \mathrm{~V}$, obvious aggregation of $\mathrm{IrO}_{\mathrm{x}}$ nanoparticles can be found on the surface. Meanwhile, the film showed micropores, some examples being pointed out by the white arrows (Figure 2c). The possible explanation for this phenomenon is that oxygen was released in the process of deposition. When the anodic potential was applied, the water was oxidized to form $\mathrm{IrO}_{\mathrm{x}}$ nanoparticles, which was reported as an excellent catalyst material for the oxygen revolution reaction $[45,46]$. With increasing the anodic limits of the potential, the deposited $\mathrm{IrO}_{\mathrm{x}}$ promoted the abundant release of oxygen, conversely, leading to the micropores. The micropores may lead to the potential drift since the water may diffuse through the pores contacting with the substrate Pt, which affect the potential measurement [47]. Thus, $0-0.7 \mathrm{~V}$ was the preferable potential range to synthesize IrOx pH sensing layer. All IrOx films were prepared in this condition in the further experiments.

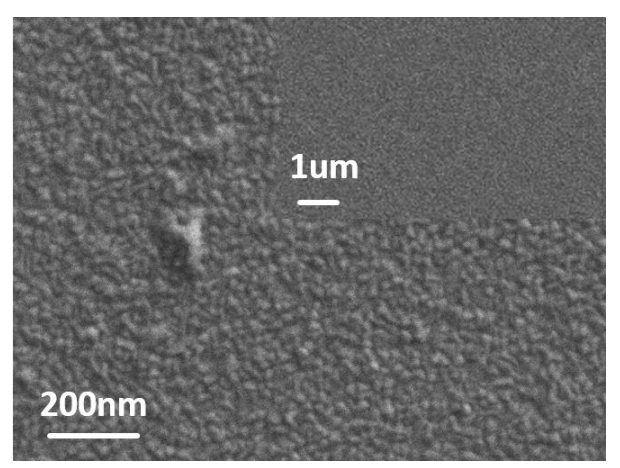

(a)

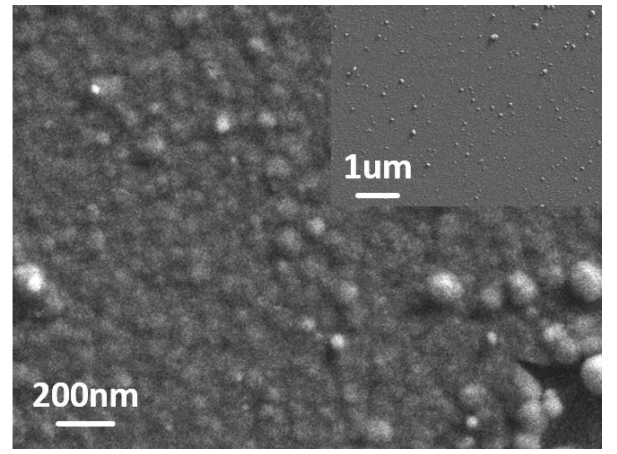

(b)

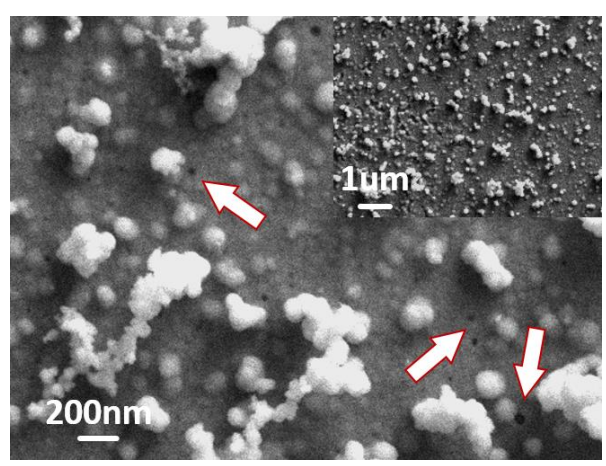

(c)

Figure 2. SEM images of the IrOx films deposited in different potential ranges: (a) $0-0.6 \mathrm{~V}$; (b) $0-0.7 \mathrm{~V}$; and (c) $0-0.75 \mathrm{~V}$.

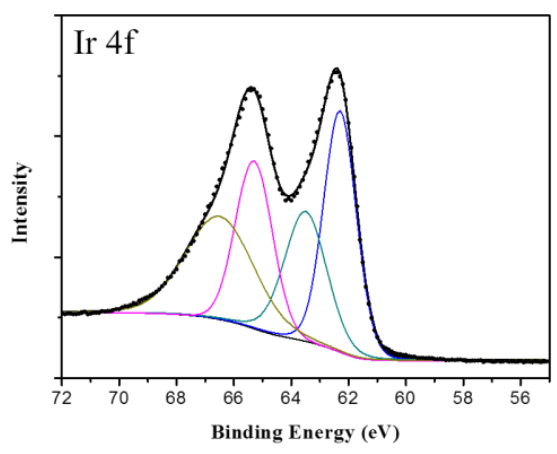

(a)

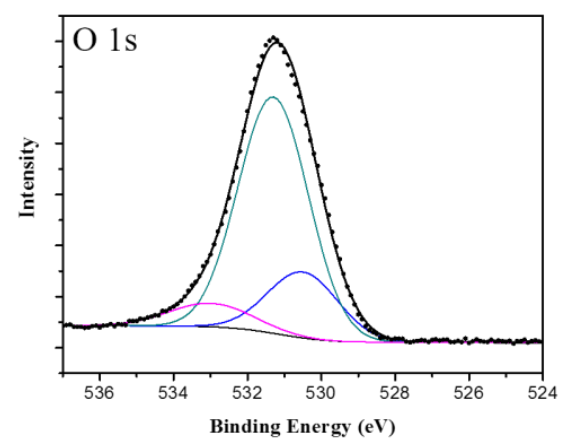

(b)

Figure 3. XPS spectra of the surface of iridium oxide film: (a) the detailed Ir4f region; and (b) the detailed O1s region. 
A XPS measurement has been performed to analyze the chemical composition of the film. The spectra were shown in Figure 3. From the high-resolution spectra of the Ir4f region (Figure 3a), it can be found that the binding energy of Ir $4 \mathrm{f} 7 / 2$ and $\operatorname{Ir} 4 \mathrm{f} 5 / 2$ lines are located at $62.4 \mathrm{eV}$ and $65.4 \mathrm{eV}$, respectively. According to the curve fitting, which was performed with the constraints described in [48], the ratio of $\operatorname{Ir}(\mathrm{III})$ to $\operatorname{Ir}(\mathrm{IV})$ was calculated to 1.38. The O 1s signal (Figure 3b) has illustrated the presence of hydroxide and water of hydration on the surface of the film, which implied the prepared film was hydrous.

\section{2. $\mathrm{pH}$ Measurement}

The sensitivity of our $\mathrm{pH}$ sensing electrode was investigated with different $\mathrm{pH}$ standard solutions, which were prepared by mixing $0.2 \mathrm{M} \mathrm{NaOH}$ and Britton-Robinson (B-R) buffer solution $\left(0.04 \mathrm{M} \mathrm{H}_{3} \mathrm{BO}_{3}, 0.04 \mathrm{M} \mathrm{H}_{3} \mathrm{PO}_{4}\right.$, and $\left.0.04 \mathrm{M} \mathrm{CH}_{3} \mathrm{COOH}\right)$ with various volume ratios. Fourteen solutions with $\mathrm{pH}$ levels from 2.22 to 11.81 were used. The electrode was successively dipped in these solutions until the potential reached an equilibrium value. Between the measurements, the electrode was washed with deionized water and dried with fresh air. The test was repeated three times. The potential response was plotted against $\mathrm{pH}$ values, as shown in Figure 4a. The $\mathrm{pH}$-sensing electrode exhibited a linear response in the test range, and the sensitivity was calculated to be $-67.60 \mathrm{mV} / \mathrm{pH}$.

The $\mathrm{pH}$ sensing mechanism of IrOx films is based on the equilibrium between oxides, in which the iridium has different oxidation states [22]. Generally, the mechanism could be described as the following reaction [49]:

$$
\mathrm{Ir}^{\mathrm{IV}} \text { oxide }+x \mathrm{H}^{+}+n \mathrm{e}^{-} \leftrightarrow \mathrm{Ir}^{\mathrm{III}} \text { oxide }+y \mathrm{H}_{2} \mathrm{O}
$$

where the values of $n, x$, and $y$ varied with the preparation method of IrOx, and are essential for determination of the potential response. Thermal oxidation or sputtering methods usually yield anhydrous IrOx films, which have near-Nernstian response with the sensitivity of about $59 \mathrm{mV} / \mathrm{pH}$, because there is an electron per proton transferred in the redox reaction. Nevertheless, a super-Nernstian response, with the sensitivity greater than $59 \mathrm{mV} / \mathrm{pH}$ will be obtained when the IrOx films were prepared by electrochemical techniques. This is because the electrochemical method generates hydrated IrOx layers, in which case the transferred electrons are less than the involved hydrogen ions. The sensitivity greater than $59 \mathrm{mV} / \mathrm{pH}$ indicates that the IrOx prepared in our work was hydrate. Similar results were demonstrated in [21], where the IrOx showed super-Nernstian response as well.

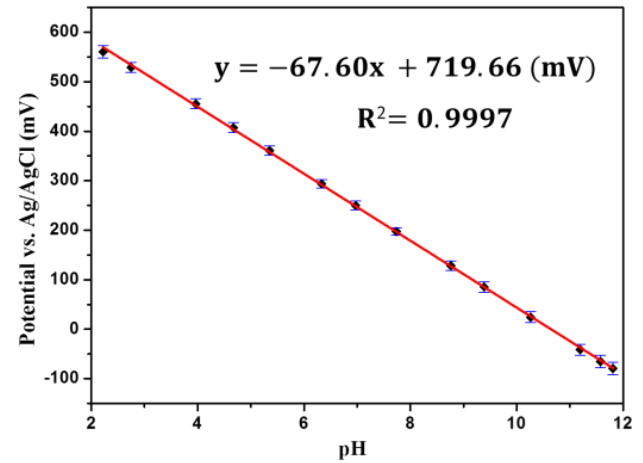

(a)

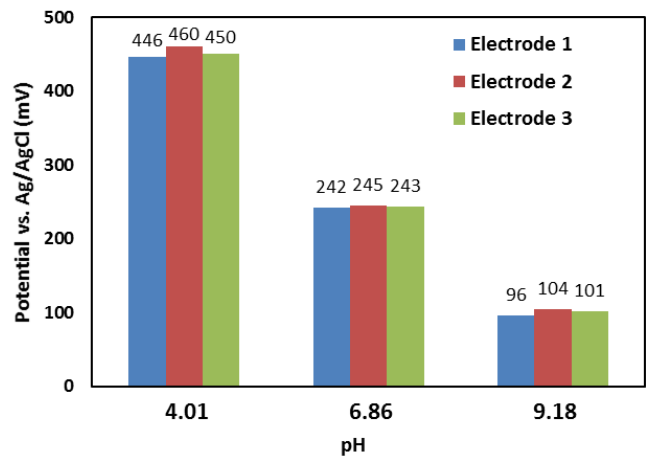

(b)

Figure 4. (a) Linear potential response of one $\mathrm{pH}$ sensing electrode from $\mathrm{pH}=2.22$ to $\mathrm{pH}=11.81$; and (b) potential responses of three electrodes in standard $\mathrm{pH}$ solutions.

We tested different electrodes in $\mathrm{pH} 4.01,6.86$, and 9.18 solutions, and the response was showed in Figure $4 \mathrm{~b}$. The relative standard deviations (RSD) of the response for these electrodes were $1.60 \%$, 
$0.63 \%$, and $4.03 \%$, indicating a good reproducibility of the electrode. It was suggested that the reproducibility and reliability of the hydrated IrOx-based $\mathrm{pH}$ sensor is associated with the hydrate level [21,50] and oxidation state [22] of the film. The test result implies that the films have a similar hydrate level and oxidation state.

A titration test was carried out to investigate the dynamic property of the $\mathrm{pH}$ sensing electrode. In the experiment, the $\mathrm{pH}$ sensing electrode was placed in a beaker containing $20 \mathrm{~mL}$ B-R buffer solution. Then, $2 \mathrm{~mL} \mathrm{NaOH}(0.2 \mathrm{M})$ solution was dropped into the beaker every $100 \mathrm{~s}$ for adjustment of the $\mathrm{pH}$ level. Magnetic stirring was employed to accelerate the progress towards the equilibrium state. A commercial $\mathrm{pH}$ meter calibrated with standard buffer solutions ( $\mathrm{pH}=4.01,6.86,9.18$ ) was employed to verify the $\mathrm{pH}$ values. During the test, the OCP of the $\mathrm{pH}$ sensing electrode was recorded by an electrochemical analyser. The potential responses of three measurement cycles were shown in Figure 5a, illustrating the potential changed quickly with the titration event. However, there are some potential differences at the same $\mathrm{pH}$ levels found in the graph, which is a common phenomenon for most metal oxide-based $\mathrm{pH}$ sensing electrodes [51]. In our case, the maximum difference in the detected $\mathrm{pH}$ levels was $16 \mathrm{mV}$, which indicates that our $\mathrm{pH}$ sensing electrode has good repeatability due to the acceptable IrOx film quality.

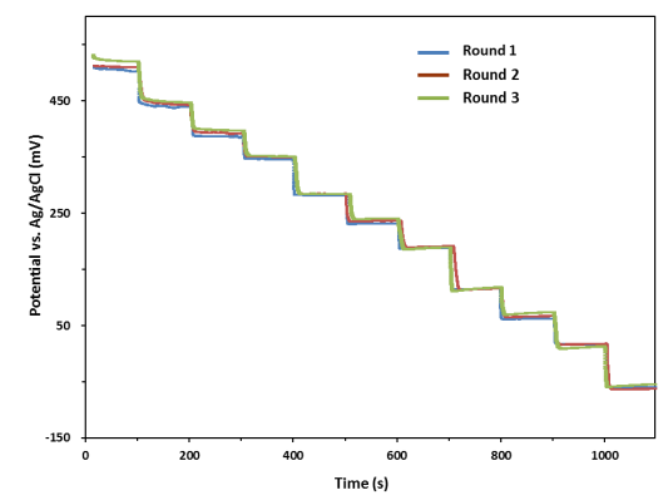

(a)
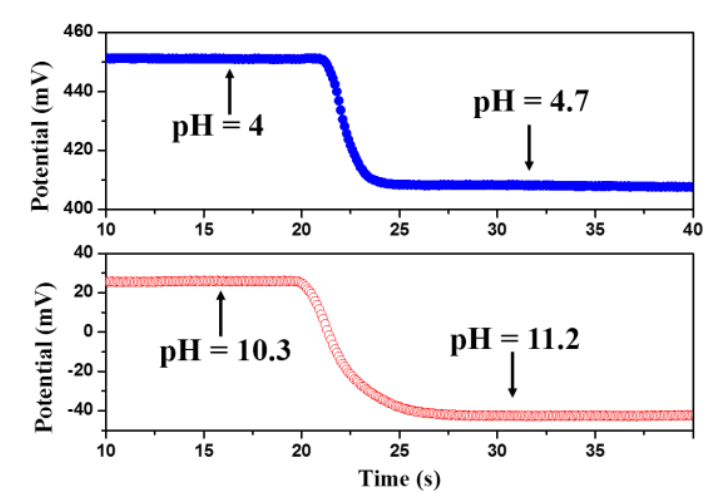

(b)

Figure 5. (a) The real-time potintial response of the $\mathrm{pH}$ sensing electrode; and (b) the response time measured from $\mathrm{pH}=4.03$ to $\mathrm{pH}=4.70$ (upper) and from $\mathrm{pH}=10.28$ to $\mathrm{pH}=11.19$ (lower).

The time required to reach $90 \%$ of the equilibrium value was defined as the response time, which is an important indicator of dynamic property. In order to know whether the sensing film has the same quick response in different environments, the response times were measured in acid and alkaline conditions, respectively. Figure $5 \mathrm{~b}$ shows the potential response changing over two transition steps, from which we can suggest that the response time was less than $7 \mathrm{~s}$. The quick response facilitates the reduction of power consumption for detection system. It was also found that a longer time was needed to reach equilibrium in the alkaline condition. This is probably due to the lower concentration change of hydrogen ions before and after titration in an alkaline environment.

\subsection{Characteristics of the Solid State Reference Electrode}

The electrochemical characteristics of the solid state reference electrode (SSRE) were investigated by cyclic voltammetry $(\mathrm{CV})$ and potentiometry, with a commercial $\mathrm{Ag} / \mathrm{AgCl}$ reference electrode (CRE) acting as the comparison. The $\mathrm{CV}$ measurements were carried out using $2 \mathrm{mM}$ ferricyanide in $0.1 \mathrm{M} \mathrm{KCl}$ as a redox couple. The SSRE or CRE was dipped in the solutions as the reference electrode, an on-chip Pt electrode as the working electrode, and a commercial Pt electrode as the counter electrode. The CV curves of SSRE and CRE, obtained in the potential range from -0.1 to $0.7 \mathrm{~V}$, at the scan rate of $50 \mathrm{mV} / \mathrm{s}$, are almost coincident as shown in Figure 6a. When a series of scan rates (20, 50, 80, 100, 150, and $200 \mathrm{mV} / \mathrm{s}$ ) were applied, the CVs of SSRE were recorded and shown in Figure 6b. The anodic 
and cathodic peak current is linearly proportional to the square root of the scan rate (Figure 6c), which matches the theory of the diffusion-controlled process.

$\mathrm{KCl}$ solutions with different concentrations were used to measure the independence to the $\mathrm{Cl}^{-}$ concentration of the SSRE. The freshly prepared electrode was dipped in the solutions and the OCP versus the CRE was recorded after an equilibrium state was reached. Figure $6 \mathrm{~d}$ shows the potential curve plotted against the logarithm of the $\mathrm{KCl}$ concentration, illustrating that the potential of the SSRE is around $24 \mathrm{mV}$ and scarcely influenced by the $\mathrm{Cl}^{-}$concentration. This fixed potential vs. CRE is probably due to the unequal concentration of $\mathrm{Cl}^{-}$for the SSRE and the CRE. The potential stability of the SSRE was evaluated by recording the OCP vs. the CRE in deionized water. Over an 86-hour measurement, the potential drift rate is $0.3 \mathrm{mV} / \mathrm{h}$ as shown in Figure $6 \mathrm{e}$. In the first $30 \mathrm{~h}$ the potential decreased faster at a rate of $0.6 \mathrm{mV} / \mathrm{h}$, and then remained stable, from which the stability of our SSRE was found to be at least $56 \mathrm{~h}$.

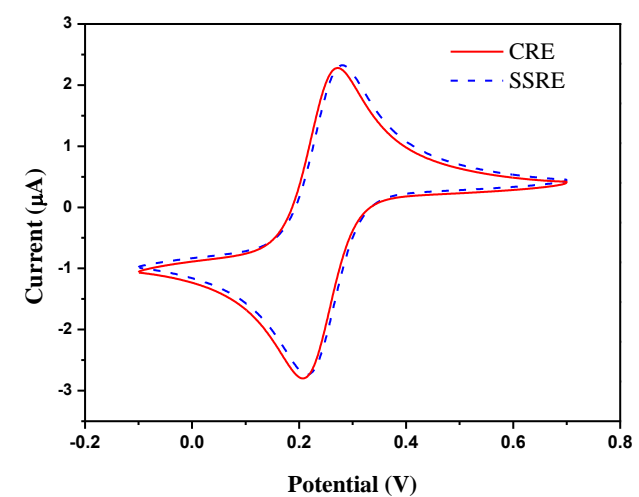

(a)

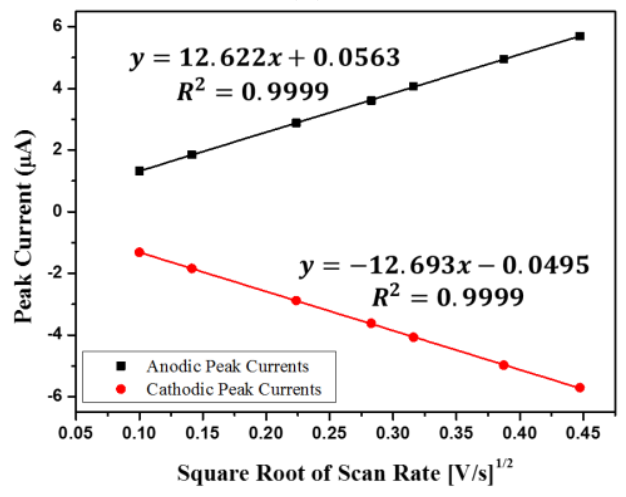

(c)

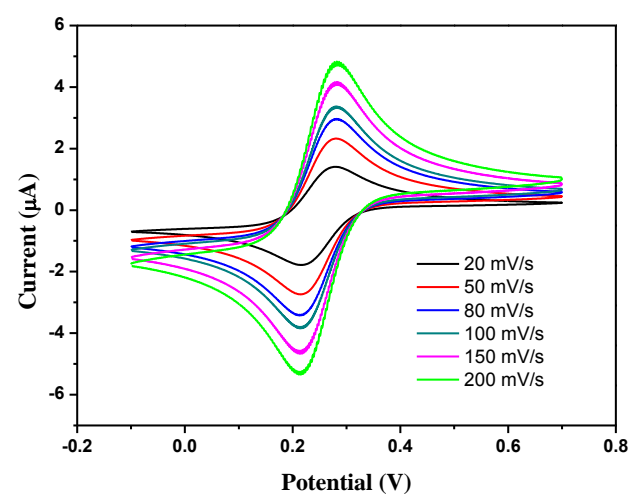

(b)

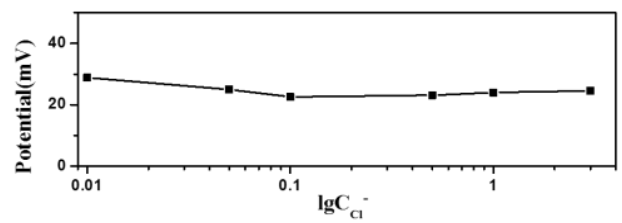

(d)

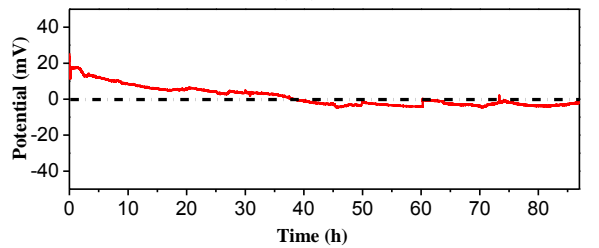

(e)

Figure 6. Electrochemical characteristics of the SSRE: (a) CVs for SSRE (-) and CRE (一) in $2 \mathrm{mM}$ ferricyanide at $50 \mathrm{mV} / \mathrm{s}$; (b) CVs for SSRE at various scan rates: 20, 50, 80, 100, 150, and $200 \mathrm{mV} / \mathrm{s}$; (c) variations of the anodic $(\boldsymbol{\square})$ and cathodic $(\bullet)$ peak currents vs. the square root of the scan rates; (d) potentials of the SSRE at $\mathrm{KCl}$ concentrations ranging from 0 to $3 \mathrm{~mol} / \mathrm{L}$; and (e) the stability of the SSRE measured in deionized water over $86 \mathrm{~h}$.

The microscopic voids existing in the epoxy offer an ionic connection between the inner KCl-agar and the sample solutions, on the other hand, the epoxy efficiently protected the inner $\mathrm{Cl}^{-}$from fast fluxing into the sample solutions. Table 1 illustrates the performance comparison of our SSRE and some other SSREs for $\mathrm{pH}$ sensing in the literature. The stability of the $\mathrm{Ag} / \mathrm{AgCl} / \mathrm{GO}$ reference electrode is 26 days in $3 \mathrm{M} \mathrm{KCl}$ solution with test intervals [52]. A LBL-PE/npPt reference electrode exhibited a stability of $50 \mathrm{~h}$ in $0.1 \mathrm{M}$ PBS [53], and a screen-printed $\mathrm{Ag} / \mathrm{AgCl} / \mathrm{KCl}$-glass SSRE showed a stability of $4 \mathrm{~h}$ in deionized water [54], while our SSRE exhibited a longer stability in deionized 
water. Additionally, the fabrication method of our SSRE is very simple, without any specific apparatus needed, and it can be used and stored freely, as the cured epoxy has good adhesiveness and high mechanical strength. Therefore, the SSRE in this work is suitable for the application in water quality monitoring, where intermittent measurement strategy is used.

Table 1. Comparison of the performance of some solid-state reference electrodes for $\mathrm{pH}$ sensing.

\begin{tabular}{cccccc}
\hline Electrode Type & Fabrication Techenique & Test Solution & Test Mode & Stability & Literature \\
\hline $\mathrm{Ag} / \mathrm{AgCl} / \mathrm{GO}$ & $\begin{array}{c}\text { Sputtering, chemical } \\
\text { chlorination, and drop casting }\end{array}$ & $3 \mathrm{M} \mathrm{KCl}$ & $\begin{array}{c}\text { Intermittent } \\
\text { (2 or 3 days' interval) }\end{array}$ & 26 days & $2015[52]$ \\
\hline $\mathrm{LBL}-\mathrm{PE} / \mathrm{npPt}$ & $\begin{array}{c}\text { Electrodeposition, } \\
\text { photo polymerization }\end{array}$ & $0.1 \mathrm{M} \mathrm{PBS}$ & Continuous & $50 \mathrm{~h}$ & $2011[53]$ \\
\hline $\mathrm{Ag} / \mathrm{AgCl} / \mathrm{KCl}$-glass & Screen printing & Deionized water & Continuous & $4 \mathrm{~h}$ & $2014[54]$ \\
\hline $\begin{array}{c}\mathrm{Ag} / \mathrm{AgCl} / \mathrm{KCl}- \\
\mathrm{agar} / \mathrm{epoxy}\end{array}$ & Drop casting & Deionized water & Continuous & $56 \mathrm{~h}$ & This work \\
\hline
\end{tabular}

\subsection{Conductivity Measurement}

A four-electrode conductivity cell is like a four-terminal precision resistor. The conductivity of water was determined by detecting the trans-impedance of the cell. A supporting circuit was constructed providing an appropriate signal to drive the cell. When a DC signal was used to excite the transducer, the interfacial capacitance between electrodes and water, which is known as an electrolytic double-layer capacitance, may cause the impedance errors, resulting in a smaller readout [55]. Thus, an alternative current with a sufficiently low amplitude is preferable. It was proved that the trans-impedance is a function of the frequency, and there is a clear conductivity-sensitive interval for medium frequencies $[41,56]$. In our case, an alternating square wave was applied to excite the cell, and $4 \mathrm{kHz}$ was selected as the optimal operating frequency. Figure 7a shows the diagram of the supporting circuit for the trans-impedance measurement. The amplitude of the drive current was controlled by adjusting the resistance of the reference resistor $\left(R_{f}\right)$. The trans-impedance of the cell was determined by detecting the excitation current passed over the two drive electrodes (ring 1 and 4 ) and the potential drop between the sensing electrodes (rings 2 and 3). The conversion from the measured conductance to the specific conductivity is derived from Equation (2):

$$
C=k \times I / E
$$

where $I$ is the excitation current through the sensor, $E$ is the voltage drop between the sensing electrodes, $k$ is the factor determined by the cell itself and called the cell constant.

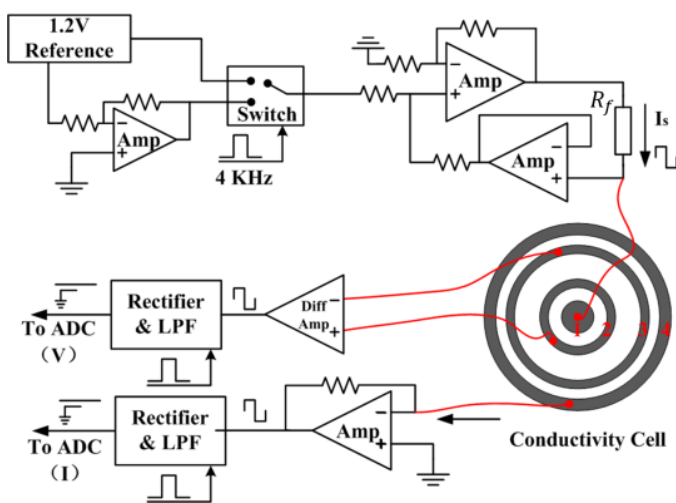

(a)

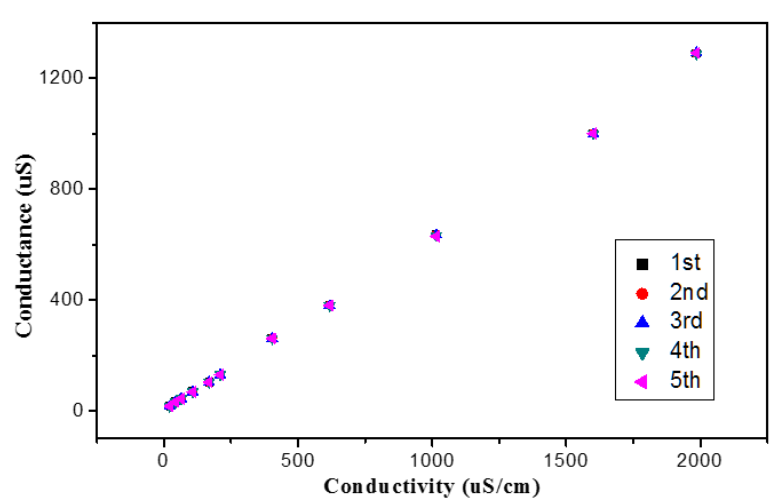

(b)

Figure 7. (a) Schematic of the trans-impedance measurement circuit; and (b) linear calibrition curve of the conductivity cell. 
The conductivity cell was calibrated with the standard solutions prepared with the recipe described in [57]. The test was repeated five times. The measured conductance was plotted against the conductivity of the solution (Figure $7 \mathrm{~b}$ ), from which the cell constant was calculated to be $1.566 \mathrm{~cm}^{-1}$. The maximum relative deviation was $3.37 \%$, which shows that the conductivity sensor has good repeatability. Meanwhile, the linear range of the conductivity sensor was from $21.43 \mu \mathrm{S} / \mathrm{cm}$ to $1.99 \mathrm{mS} / \mathrm{cm}$, which covers the conductivities of usual drinking water [1].

\subsection{Temperature Measurement}

Motivated by the need of accurate temperature measurement, the RTD was designed as a three-terminal structure to prevent the errors caused by lead impedance. The temperature sensor was calibrated against a commercial temperature probe using a water bath. The resistance of the RTD was measured with the multi-meter in the test. The relationship of the resistance of RTD and temperature is shown in Figure 8 . The sensitivity $\left(5.46 \Omega /{ }^{\circ} \mathrm{C}\right)$ and good linearity $\left(R^{2}=0.9999\right)$ indicate that the RTD could be used to detect temperature accurately, compensating for the thermal errors for the measurements of $\mathrm{pH}$ and conductivity.

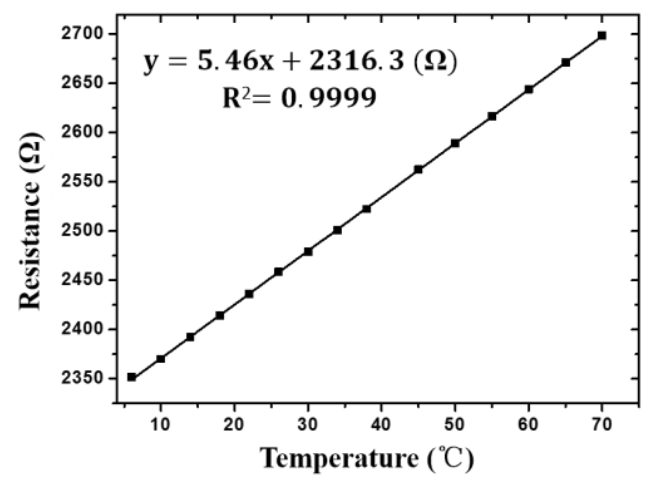

Figure 8. The linear relationship between resistance of RTD and temperature.

\section{Conclusions}

In this paper, we proposed a multi-parameter sensor chip, on which three different sensors were distributed. The chip size was approximately $7 \mathrm{~mm} \times 8 \mathrm{~mm}$. The circular shape for the conductivity sensor was designed to prevent the bipolar square wave from disturbing the other electrodes. Hydrous IrOx film was electrodeposited on the surface of the Pt electrode as the $\mathrm{pH}$ sensing material, coupling with a miniaturized solid-state reference electrode. The on-chip sensors exhibited good performance as intended. The $\mathrm{pH}$ sensor showed a sensitivity of $-67.60 \mathrm{mV} / \mathrm{pH}$, and had a short response time. The conductivity cell had a sensitivity of $1.566 \mathrm{~cm}^{-1}$, which is suitable for the detection of drinking water. The temperature sensor had a high sensitivity of $5.46 \Omega /{ }^{\circ} \mathrm{C}$. The integrated sensing chip could be manufactured in batches, which makes it economical and suitable for application in portable or online detection systems of water quality. Further work will focus on the optimization and fusion of multiple transducers, as well as the construction of the water quality monitoring system. Lifetime is the most important issue for on-site measurement, so we will mainly aim for the extension of the sensor lifetime. A low-power consumption circuit will be developed as the data acquisition node, so that the sensor can be used in water quality monitoring.

Acknowledgments: The authors acknowledge the financial support of the National Natural Science Foundation (No. 61671433) and the National Basic Research Program of China (973 Program) (No. 2015CB352100).

Author Contributions: Bo Zhou conceived the method, performed the experiments, analyzed the results and wrote the manuscript. Chao Bian supervised all the research work of Bo Zhou. Jianhua Tong advised on the research direction and offered instructions on the testing of the sensor. Shanhong Xia provided financial support for this work. 
Conflicts of Interest: The authors declare no conflict of interest.

\section{References}

1. Banna, M.H.; Najjaran, H.; Sadiq, R.; Imran, S.A.; Rodriguez, M.J.; Hoorfar, M. Miniaturized water quality monitoring $\mathrm{pH}$ and conductivity sensors. Sens. Actuators B Chem. 2014, 193, 434-441. [CrossRef]

2. Yosemitech. Yosemitech Homepage: Y4000. Available online: http://www.yosemitech.com/product-20 (accessed on 9 November 2016).

3. Hsu, L.; Selvaganapathy, P.R.; Brash, J.; Fang, Q.; Xu, C.Q.; Deen, M.J.; Chen, H. Development of a low-cost hemin-based dissolved oxygen sensor with anti-biofouling coating for water monitoring. IEEE Sens. J. 2014, 14, 3400-3407. [CrossRef]

4. Hsu, L.H.H.; Hoque, E.; Kruse, P.; Ravi Selvaganapathy, P. A carbon nanotube based resettable sensor for measuring free chlorine in drinking water. Appl. Phys. Lett. 2015, 106, 063102. [CrossRef]

5. Zhuiykov, S.; Brien, D.O.; Best, M.; O’Brien, D.; Best, M. Water quality assessment by an integrated multi-sensor based on semiconductor $\mathrm{RuO}_{2}$ nanostructures. Meas. Sci. Technol. 2009, 20, 095201. [CrossRef]

6. Guijarro, C.; Fuchs, K.; Bohrn, U.; Evamaria, S.; Stefan, W. Simultaneous detection of multiple bioactive pollutants using a multiparametric biochip for water quality monitoring. Biosens. Bioelectron. 2015, 72, 71-79. [CrossRef] [PubMed]

7. Wang, J.; Bian, C.; Tong, J.; Sun, J.; Xia, S. Acid/L-cysteine/gold nanoparticle modified microelectrode for simultaneous detection of copper and lead. Thin Solid Films 2012, 520, 6658-6663. [CrossRef]

8. Organization, World Health. Guidelines for Drinking-Water Quality: Fourth Edition. Available online: http://www.who.int/water_sanitation_health/publications/dwqguidelines-4/en (accessed on 9 November 2016).

9. Qin, Y.; Kwon, H.-J.; Howlader, M.M.R.; Deen, M.J. Microfabricated electrochemical pH and free chlorine sensors for water quality monitoring: Recent advances and research challenges. RSC Adv. 2015, 5, 69086-69109. [CrossRef]

10. Zheng, Y.; Chen, L.H.; Dong, X.; Yang, J.; Long, H.Y.; So, P.L.; Chan, C.C. Miniature pH Optical Fiber Sensor Based on Fabry-Perot Interferometer. IEEE J. Sel. Top. Quantum Electron. 2016, 22, 331-335. [CrossRef]

11. Bahari, N.; Zain, A.M.; Abdullah, A.Z.; Bien, D.; Sheng, C.; Othman, M. Study on pH sensing properties of $\mathrm{RF}$ magnetron sputtered tantalum pentoxide $\left(\mathrm{Ta}_{2} \mathrm{O}_{5}\right)$ thin film. In Proceedings of the 2010 IEEE International Conference on Semiconductor Electronics (ICSE), Malacca, Malaysia, 28-30 June 2010; pp. 76-78.

12. Zhao, R.; Xu, M.; Wang, J.; Chen, G. A pH sensor based on the $\mathrm{TiO}_{2}$ nanotube array modified Ti electrode. Electrochim. Acta 2010, 55, 5647-5651. [CrossRef]

13. Gerlach, G.; Guenther, M.; Sorber, J.; Suchaneck, G.; Arndt, K.F.; Richter, A. Chemical and pH sensors based on the swelling behavior of hydrogels. Sens. Actuators B Chem. 2005, 111-112, 555-561. [CrossRef]

14. Sardarinejad, A.; Maurya, D.K.; Alameh, K. Physical The effects of sensing electrode thickness on ruthenium oxide thin-film pH sensor. Sens. Actuators A. Phys. 2014, 214, 15-19. [CrossRef]

15. Uria, N.; Abramova, N.; Bratov, A.; Muñoz-Pascuall, F.X.; Baldrich, E. Miniaturized metal oxide pH sensors for bacteria detection. Talanta 2016, 147, 364-369. [CrossRef] [PubMed]

16. Pan, C.; Chou, J.; Sun, T.; Hsiung, S. Development of the real-time pH sensing system for array sensors. Sens. Actuators B Chem. 2005, 108, 870-876. [CrossRef]

17. Kuo, L.M.; Chou, Y.C.; Chen, K.N.; Lu, C.C.; Chao, S. A precise $\mathrm{pH}$ microsensor using RF-sputtering $\mathrm{IrO}_{2}$ and $\mathrm{Ta}_{2} \mathrm{O}_{5}$ films on Pt-electrode. Sens. Actuators B Chem. 2014, 193, 687-691. [CrossRef]

18. Huang, X.R.; Ren, Q.Q.; Yuan, X.J.; Wen, W.; Chen, W.; Zhan, D.P. Iridium oxide based coaxial pH ultramicroelectrode. Electrochem. Commun. 2014, 40, 35-37. [CrossRef]

19. Wang, M.; Yao, S.; Madou, M. A long-term stable iridium oxide pH electrode. Sens. Actuators B Chem. 2002, 81, 313-315. [CrossRef]

20. Nguyen, C.M.; Huang, W.D.; Rao, S.; Cao, H.; Tata, U.; Chiao, M.; Chiao, J.C. Sol-gel iridium oxide-based pH sensor array on flexible polyimide substrate. IEEE Sens. J. 2013, 13, 3857-3864. [CrossRef]

21. Nguyen, C.M.; Rao, S.; Seo, Y.; Schadt, K.; Hao, Y.; Chiao, J.; Member, S. Micro pH Sensors Based on Iridium Oxide Nanotubes. IEEE Trans. Nanotechnol. 2014, 13, 945-953. [CrossRef]

22. Steegstra, P.; Ahlberg, E. Influence of oxidation state on the $\mathrm{pH}$ dependence of hydrous iridium oxide films. Electrochim. Acta 2012, 76, 26-33. [CrossRef] 
23. Kim, T.Y.; Yang, S. Fabrication method and characterization of electrodeposited and heat-treated iridium oxide films for pH sensing. Sens. Actuators B Chem. 2014, 196, 31-38. [CrossRef]

24. Yamanaka, K. Anodically electrodeposited iridium oxide films (AEIROF's) from alkaline solutions for electrochromic display devices. Jpn. J. Appl. Phys. 1989, 28, 632-637. [CrossRef]

25. Bitziou, E.; O'Hare, D.; Patel, B.A. Simultaneous detection of $\mathrm{pH}$ changes and histamine release from oxyntic glands in isolated stomach. Anal. Chem. 2008, 80, 8733-8740. [CrossRef] [PubMed]

26. Nadappuram, B.P.; Mckelvey, K.; Al Botros, R.; Colburn, A.W.; Unwin, P.R. Fabrication and Characterization of Dual Function Nanoscale pH-Scanning Ion Conductance Microscopy (SICM) Probes for High Resolution pH Mapping. Anal. Chem. 2013, 85, 8070-8074. [CrossRef] [PubMed]

27. Bezbaruah, A.N.; Zhang, T.C. Fabrication of Anodically Electrodeposited Iridium Oxide Film pH Microelectrodes for Microenvironmental Studies. Anal. Chem. 2002, 74, 5726-5733. [CrossRef] [PubMed]

28. Steegstra, P.; Ahlberg, E. Involvement of nanoparticles in the electrodeposition of hydrous iridium oxide films. Electrochim. Acta 2012, 68, 206-213. [CrossRef]

29. Elsen, H.A.; Monson, C.F.; Majda, M. Effects of Electrodeposition Conditions and Protocol on the Properties of Iridium Oxide pH Sensor Electrodes. J. Electrochem. Soc. 2009, 156, F1-F6. [CrossRef]

30. Zhao, Y.; Vargas-barbosa, N.M.; Hernandez-pagan, E.A.; Mallouk, T.E. Anodic Deposition of Colloidal Iridium Oxide Thin Films from Hexahydroxyiridate(IV) Solutions. Small 2011, 7, 2087-2093. [CrossRef] [PubMed]

31. Zhao, Y.; Hernandez-Pagan, E.A.; Vargas-Barbosa, N.M.; Dysart, J.L.; Mallouk, T.E. A High Yield Synthesis of Ligand-Free Iridium Oxide Nanoparticles with High Electrocatalytic Activity. J. Phys. Chem. Lett. 2011, 2, 402-406. [CrossRef]

32. Khalil, M.; Wang, S.; Yu, J.; Lee, R.L.; Liu, N. Electrodeposition of Iridium Oxide Nanoparticles for $\mathrm{pH}$ Sensing Electrodes. J. Electrochem. Soc. 2016, 163, B485-B490. [CrossRef]

33. Shitanda, I.; Kiryu, H.; Itagaki, M. Improvement in the long-term stability of screen-printed planar type solid-state $\mathrm{Ag} / \mathrm{AgCl}$ reference electrode by introducing poly (dimethylsiloxane) liquid junction. Electrochim. Acta 2011, 58, 528-531. [CrossRef]

34. Kim, S.K.; Lim, H.; Chung, T.D.; Kim, H.C. A miniaturized electrochemical system with a novel polyelectrolyte reference electrode and its application to thin layer electroanalysis. Sens. Actuators B Chem. 2006, 115, 212-219. [CrossRef]

35. Huang, I.Y.; Huang, R.S. Fabrication and characterization of a new planar solid-state reference electrode for ISFET sensors. Thin Solid Films 2002, 406, 255-261. [CrossRef]

36. Adachi, T.; Suzuki, H. Dynamic feedback regulation of the potential of a microfabricated liquid-junction $\mathrm{Ag} / \mathrm{AgCl}$ reference electrode. Sens. Actuators B Chem. 2011, 156, 228-235. [CrossRef]

37. Li, W.; Liu, F.Y.; Wang, K.Y.; Wen, Z.Y. The Fabrication and Experiment of a Four-Electrode Conductivity Sensor for Fresh Water. Key Eng. Mater. 2011, 483, 341-344. [CrossRef]

38. Ramos, P.M.; Pereira, J.M.D.; Member, S.; Ramos, H.M.G. A Four Terminal Water Quality Monitoring Conductivity Sensor. IEEE Trans. Instrum. Meas. 2008, 57, 577-583. [CrossRef]

39. Kim, M.; Choi, W.; Lim, H.; Yang, S. Integrated micro fluidic-based sensor module for real-time measurement of temperature, conductivity, and salinity to monitor reverse osmosis. DES 2013, 317, 166-174. [CrossRef]

40. He, D.; Shannon, M.A.; Miller, N.R. Micromachined Silicon Electrolytic Conductivity Probes with Integrated Temperature Sensor. IEEE Sens. J. 2005, 5, 1185-1196.

41. Hyldgård, A.; Ólafsdóttir, Í.; Olesen, M.; Hedegaard, T.; Hansen, O.; Thomsen, E.V. FISH \& CHIPS: Four Electrode Conductivity/Salinity Sensor on a Silicon Multi-sensor Chip for Fisheries Research. In Proceedings of the IEEE SENSORS, Irvine, CA, USA, 30 October-3 November 2005.

42. Broadbent, H.A.; Ivanov, S.Z.; Fries, D.P. Fabrication of a LCP-based conductivity cell and resistive temperature device via PCB MEMS technology. J. Micromech. Microeng. 2007, 17, 722-729. [CrossRef]

43. Broadbent, H.A.; Ivanov, S.Z.; Fries, D.P. A miniature, low cost CTD system for coastal salinity measurements. Meas. Sci. Technol. 2007, 18, 3295-3302. [CrossRef]

44. Negi, S.; Bhandari, R.; Solzbacher, F. Morphology and Electrochemical Properties of Activated and Sputtered Iridium Oxide Films for Functional Electrostimulation. J. Sens. Technol. 2012, 2, 138-147. [CrossRef]

45. Lee, B.-S.; Ahn, S.H.; Park, H.-Y.; Choi, I.; Yoo, S.J.; Kim, H.-J.; Henkensmeier, D.; Kim, J.Y.; Park, S.; Nam, S.W.; et al. Development of electrodeposited $\mathrm{IrO}_{2}$ electrodes as anodes in polymer electrolyte membrane water electrolysis. Appl. Catal. B Environ. 2015, 179, 285-291. [CrossRef] 
46. Blakemore, J.D.; Mara, M.W.; Kushner-lenho, M.N.; Schley, N.D.; Konezny, S.J.; Rivalta, I.; Negre, C.F.A.; Snoeberger, R.C.; Kokhan, O.; Huang, J.; et al. Characterization of an Amorphous Iridium Water-Oxidation Catalyst Electrodeposited from Organometallic Precursors. Inorg. Chem. 2013, 52, 1860-1871. [CrossRef] [PubMed]

47. Zhuiykov, S. Morphology of Pt-doped nanofabricated $\mathrm{RuO}_{2}$ sensing electrodes and their properties in water quality monitoring sensors. Sens. Actuators B Chem. 2009, 136, 248-256. [CrossRef]

48. Casella, I.G.; Contursi, M.; Toniolo, R. Anodic electrodeposition of iridium oxide particles on glassy carbon surfaces and their electrochemical/SEM/XPS characterization. J. Electroanal. Chem. 2015, 736, 147-152. [CrossRef]

49. Roushani, M.; Farokhi, S. Amperometric Detection of Isoprenaline Based on Glassy Carbon Electrode Modified by Iridium Oxide Nanoparticles. J. Braz. Chem. Soc. 2015, 26, 1034-1042. [CrossRef]

50. Yao, S.; Wang, M.; Madou, M. A pH Electrode Based on Melt-Oxidized Iridium Oxide. J. Electrochem. Soc. 2001, 148, H29-H36. [CrossRef]

51. Huang, W.D.; Cao, H.; Deb, S.; Chiao, M.; Chiao, J.C. A flexible pH sensor based on the iridium oxide sensing film. Sens. Actuators A Phys. 2011, 169, 1-11. [CrossRef]

52. Kim, T.Y.; Hong, S.A.; Yang, S. A solid-state thin-film Ag/ AgCl reference electrode coated with graphene oxide and its use in a pH sensor. Sensors 2015, 15, 6469-6482. [CrossRef] [PubMed]

53. Noh, J.; Park, S.; Boo, H.; Kim, C.; Dong, T. Nanoporous platinum solid-state reference electrode with layer-by-layer polyelectrolyte junction for $\mathrm{pH}$ sensing chip. Lab Chip 2011, 11, 664-671. [CrossRef] [PubMed]

54. Manjakkal, L.; Cvejin, K.; Kulawik, J.; Zaraska, K.; Szwagierczak, D.; Socha, R.P. Fabrication of thick film sensitive $\mathrm{RuO}_{2}-\mathrm{TiO}_{2}$ and $\mathrm{Ag} / \mathrm{AgCl} / \mathrm{KCl}$ reference electrodes and their application for $\mathrm{pH}$ measurements. Sens. Actuators B Chem. 2014, 204, 57-67. [CrossRef]

55. Broadbent, H.A.; Ketterl, T.P.; Reid, C.S. A miniature rigid/flex salinity measurement device fabricated using printed circuit processing techniques. J. Micromech. Microeng. 2010, 20, 085008. [CrossRef]

56. Hyldgård, A.; Birkelund, K.; Janting, J.; Thomsen, E.V. Direct media exposure of MEMS multi-sensor systems using a potted-tube packaging concept. Sens. Actuators A Phys. 2008, 142, 398-404. [CrossRef]

57. Standards Press of China. Test Solutions of Electrolytic Conductivity Analyzer-Preparation Method of Sodium Chloride Solutions (GB/T 27503-2011); Standards Press of China: Beijing, China, 2011; pp. 1-10.

(C) 2017 by the authors; licensee MDPI, Basel, Switzerland. This article is an open access article distributed under the terms and conditions of the Creative Commons Attribution (CC-BY) license (http://creativecommons.org/licenses/by/4.0/). 